\title{
ANALISIS PERCEPATAN DURASI PEKERJAAN BASEMENT SEMI TOP DOWN DENGAN METODE TIME COST TRADE OFF
}

\author{
Lucy Setiawan $^{1}$ dan Jane Sekarsari Tamtana² \\ ${ }^{1}$ Program Studi Sarjana Teknik Sipil, Universitas Tarumanagara, Jl. Letjen S. Parman No.1 Jakarta \\ lucy.325150027@stu.untar.ac.id \\ ${ }^{2}$ Jurusan Teknik Sipil, Universitas Trisakti, Jl. Kiai Tapa No. 1 Jakarta \\ tamtana.js@gmail.com
}

Masuk: 10-01-2020 revisi: 26-01-2020, diterima untuk diterbitkan: 19-02-2020

\begin{abstract}
Contractor gets a penalty for a delayed project. A stipulation of penalty is stated on Perpres No. 16 Tahun 2018. Indonesia One project was selected for research because the project was applying semi Top Down Method for its basement and the project was facing a delay on South Tower Basement that could cause a penalty. The applied method to speed up the implementation is time cost trade off; strategy:to increase the number of workers and to prolong the working time. The purpose of the research is to analyze the acceleration, and to compare which can result in minimum cost. The research shows that the excavation work at $C$ Zone can be accelerated from normal duration 44 days to 37 days by increasing the number of workers; this results in lower crash cost in the amount of $R p$ 11.927.090 compare to prolong working time in the amount of Rp 45.796.186. The column reinforcement work at $C$ Zone can be accelerated from normal duration 54 days to 37 days by increasing the number of workers; this results in lower crash cost in the amount of Rp 15.271.375 compare to prolong working time in the amount of Rp 65.019.330.
\end{abstract}

Keywords: acceleration construction project; time cost trade off; increase the number of workers; prolong the working time

\begin{abstract}
ABSTRAK
Keterlambatan durasi akan menyebabkan kontraktor dikenakan denda keterlambatan. Perihal tentang denda keterlambatan tertulis dalam Perpres No.16 Tahun 2018. Proyek Indonesia 1 dipilih sebagai objek penelitian karena menggunakan metode semi Top Down pada pelaksanaan basement dan proyek tersebut mengalami keterlambatan durasi pada pekerjaan basement Tower Selatan. Metode percepatan yang digunakan untuk mempercepat durasi proyek adalah metode time cost trade off. Strategi yang digunakan ialah dengan menambah jumlah pekerja dan menambah jumlah jam kerja. Tujuan penelitian adalah menganalisis percepatan dan mendapatkan strategi dengan biaya percepatan yang lebih murah. Hasil penelitian menunjukan bahwa pekerjaan galian Zona $\mathrm{C}$ dapat dipercepat sebanyak tujuh hari dengan penambahan jumlah tenaga kerja; menghasilkan biaya percepatan yang lebih murah dengan nilai Rp 11.927.090 dibandingkan dengan menambah jumlah jam kerja dengan biaya percepatan sebesar Rp 45.796.186. Pekerjaan penulangan kolom Zona C dapat dipercepat dari durasi normal 54 hari menjadi 47 hari dengan penambahan jumlah tenaga kerja; menghasilkan biaya percepatan yang lebih murah dengan nilai Rp 15.271.375 dibandingkan dengan menambah jumlah jam kerja dengan biaya percepatan debesar Rp 65.019.330.
\end{abstract}

Kata kunci: percepatan proyek konstruksi; time cost trade off; menambah jumlah pekerja; menambah jumlah jam kerja

\section{PENDAHULUAN}

Ketika lahan proyek terbatas untuk melakukan perluasan lahan horizontal, maka yang dapat dilakukan adalah dengan melakukan perluasan lahan vertikal atau membuat basement. Metode konstruksi pelaksanaan basement yang biasa digunakan adalah metode bottom up. Pada metode bottom up, pekerjaan dilakukan dari menggali tanah sampai kedalaman elevasi rencana galian open cut tanpa adanya perkuatan). Namun, hal itu menyebabkan metode bottom up kurang layak untuk pekerjaan galian yang dalam atau dikenal sebagai galian open cut. Galian open cut tanpa adanya perkuatan dapat menyebabkan kelongsoran tanah (Hamakareem, 2019)

Salah satu metode yang sedang berkembang di Indonesia adalah metode konstruksi top down. Berdasarkan arti kata "top down", sebenarnya kita sudah dapat mengetahui proses pelaksanaannya, yaitu pekerjaan dimulai dari basement 
yang teratas dan dilanjutkan lapis demi lapis sampai kedalaman basement yang direncanakan dan dikerjakan bersamaan dengan pekerjaan galian basement. Dalam pelaksanaannya, juga dikenal metode "semi top down". Pada saat wawancara pribadi dengan Hamonangan Marpaung, beliau mengatakan bahwa pada metode ini, struktur bawah (basement) dan struktur atas (bangunan) tidak boleh dikerjakan pada saat yang bersamaan. Struktur atas dikerjakan setelah struktur bawah telah mencapai progress $100 \%$. Semakin bertambahnya gedung-gedung bertingkat tinggi sehingga lahan yang sempit, pekerjaan galian yang dalam, dan harga tanah yang semakin mahal, pemilihan basement dengan metode top down dapat menjadi salah satu alternatif yang dapat dipertimbangkan untuk digunakan.

Namun, dalam pelaksanaannya metode top down atau semi top down memiliki kekurangan diantaranya: memiliki tingkat kesulitan yang tinggi, biaya yang diperlukan lebih mahal karena membutuhkan king post saat pelaksanaan, diperlukan ketelitian dan ketepatan, dan diperlukan pengetahuan spesifik untuk mengendalikan proyek (Tanubrata, 2015). Kekurangan yang dimiliki metode top down dapat menjadi salah satu faktor penyebab keterlambatan. Apabila terjadi keterlambatan rencana jadwal dengan realisasi di lapangan, maka hal yang biasa terjadi di lapangan ialah kontraktor akan dikenakan denda keterlambatan.

Percepatan durasi pekerjaan perlu dilakukan apabila proyek telah mengalami keterlambatan. Metode percepatan yang dapat digunakan ialah metode Time Cost Trade Off. Metode ini menyediakan lima cara yang dapat digunakan untuk mempercepat durasi pekerjaan, antara lain: penambahan jam kerja, penambahan tenaga kerja, penambahan produktivitas alat, pemilihan metode konstruksi yang efektif, dan pemilihan sumber daya manusia yang berkualitas (Priyo, 2018)

\section{Rumusan Masalah}

1. Bagaimana analisis percepatan durasi pekerjaan basement top down proyek Indonesia 1 dengan metode time cost trade off?

2. Strategi manakah yang menghasilkan percepatan durasi pekerjaan basement top down dengan biaya terjangkau dan waktu yang cepat?

\section{Tujuan Penelitian}

1. Melakukan analisis percepatan pekerjaan basement top down proyek Indonesia 1 dengan metode time cost trade off pada proyek gedung bertingkat.

2. Mendapatkan strategi yang tepat untuk digunakan dengan mempertimbangkan biaya dalam percepatan pekerjaan basement top down pada proyek gedung bertingkat.

\section{Jaringan Kerja}

Jaringan kerja yang dipakai pada penelitian ini ialah PDM (Precedence Diagram Method). PDM termasuk dalam klasifikasi AON (activity on node). AON digambarkan dalam node yang berbentuk segi empat, sedangkan anak panah hanya sebagai petunjuk hubungan antar kegiatan - kegiatan yang bersangkutan. Kegiatan dan peristiwa ditulis dalam node yang berbentuk kotak segiempat. Kotak tersebut menandai suatu kegiatan, dengan demikian harus dicantumkan identitas kegiatan dan kurun waktunya. Setiap node memiliki dua peristiwa, yaitu peristiwa awal dan peristiwa akhir. Ruangan dalam node terbagi dalam bagian kecil berisi informasi mengenai nama kegiatan dan keterangan spesifik lainnya berupa kurun waktu, tanggal mulai dan tanggal selesai. Namun, informasi yang sering muncul yaitu mengenai muncul dan selesainya suatu kegiatan $(\mathrm{ES}=$ Early Start, LS = Late Start, EF = Early Finish, dan LF = Late Finish) (Tanubrata, 2015)

\begin{tabular}{|c|c|c|}
\hline ES & ID & EF \\
\hline \multicolumn{3}{|c|}{ LABEL } \\
\hline LS & D & LF \\
\hline
\end{tabular}

Gambar 1. Node Diagram Presedence

Langkah kerja metode PDM:

- Membuat denah noda sesuai dengan jumlah kegiatan 
- Menghubungkan noda (kegiatan) sesuai dengan konstrain menggunakan anah panah

- Lengkapi detail atribut pada setiap noda

- $\quad$ Hitung ES, EF, LS, dan LF untuk mengidentifikasi kegiatan kritis

\section{Konstrain dan Lag pada PDM.}

Pada metode PDM, aktivitas digambarkan melalui noda, anak panah hanyalah memberikan hubungan antar kegiatan dan bukan untuk menyatakan kurun waktu penyelesaian kegiatan. Hubungan - hubungan antar kegiatan bisa berupa berbagai macam kemungkinan yang disebut konstrain. Konstrain menunjukkan hubungan antar kegiatan dengan satu garis dari node terdahulu ke node berikutnya. Satu konstrain hanya dapat memiliki dua node atau hanya dapat menghubungkan dua node. Setiap node memiliki dua ujung, yaitu ujung awal atau mulai $=(\mathrm{S})$ dan ujung akhir atau selesai = ( F ), maka ada 4 macam konstrain, yaitu awal ke awal (SS), awal ke akhir (SF), akhir ke akhir (FF) dan akhir ke awal (FS). Pada garis konstrain dibubuhkan penjelasan mengenai waktu mendahului (lead) atau terlambat tertunda (lag) (Tanubrata, 2015)

\section{Konstrain Start to Start (SS).}

Memberikan penjelasan hubungan antara mulainya suatu kegiatan dengan mulainya kegiatan terdahulu. Atau SS(i-j) = b yang berarti suatu kegiatan (j) mulai setelah hari kegiatan terdahulu (i) mulai. Konstrain semacam ini terjadi bila sebelum kegiatan terdahulu selesai 100 persen, maka kegiatan (j) boleh mulai. Atau kegiatan (j) boleh mulai setelah bagian tertentu dari kegiatan (i) selesai. Besar angka b tidak boleh melebihi angka kurun waktu kegiatan terdahulu, karena per definisi b adalah sebagian dari kurun waktu kegiatan terdahulu. Jadi, di sini terjadi kegiatan tumpang tindih (Tanubrata, 2015)

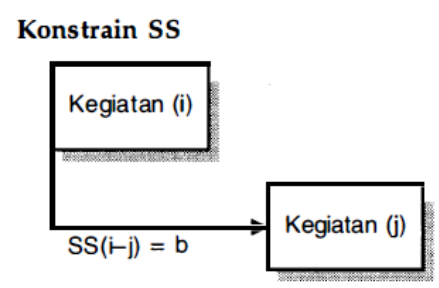

Gambar 2. Konstrain Start to Start.

\section{Konstrain Start to Finish (SF)}

Menjelaskan hubungan antara selesainya kegiatan dengan mulainya kegiatan terdahulu. Dituliskan dengan $\mathrm{SF}(\mathrm{i}-\mathrm{j})=$ d, yang berarti suatu kegiatan (j) selesai setelah d hari kegiatan (i) terdahulu mulai. Jadi, dalam hal ini sebagian dari

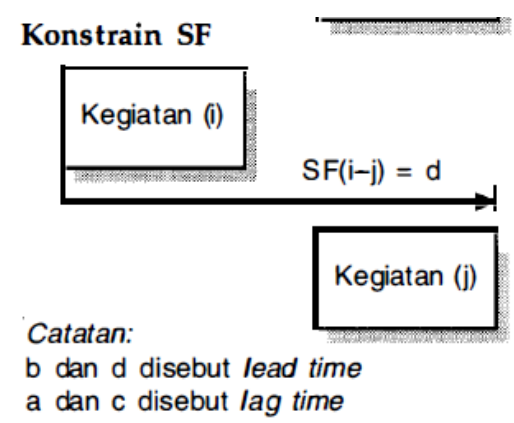

porsi kegiatan terdahulu harus selesai sebelum bagian akhir kegiatan yang dimaksud boleh diselesaikan.

\section{Gambar 3. Konstrain Start to Finish}

\section{Konstrain Finish to Start (FS)}

Konstrain ini memberikan penjelasan hubungan antara mulainya suatu kegiatan dengan selesainya kegiatan terdahulu. Dirumuskan sebagai $F S(i-j)=a$ yang berarti kegiatan (j) mulai a hari, setelah kegiatan yang mendahuluinya (i) selesai (Tanubrata, 2015) 


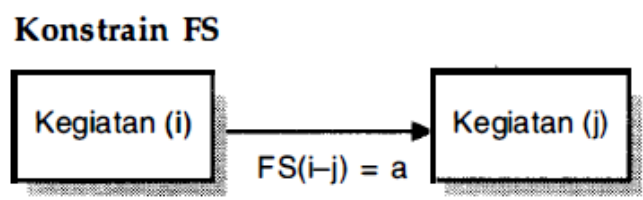

Gambar 4. Konstrain Finish to Start.

\section{Konstrain Finish to Finish (FF)}

Memberikan penjelasan hubungan antara selesainya suatu kegiatan dengan selesainya kegiatan terdahulu atau $\mathrm{FF}(\mathrm{i}-$ $\mathrm{j})$ = c yang berarti suatu kegiatan (j) selesai setelah c hari kegiatan terdahulu (i) selesai. Konstrain semacam ini mencegah selesainya suatu kegiatan mencapai $100 \%$, sebelum kegiatan yang terdahulu telah sekian $(=\mathrm{c})$ hari selesai (Tanubrata, 2015)

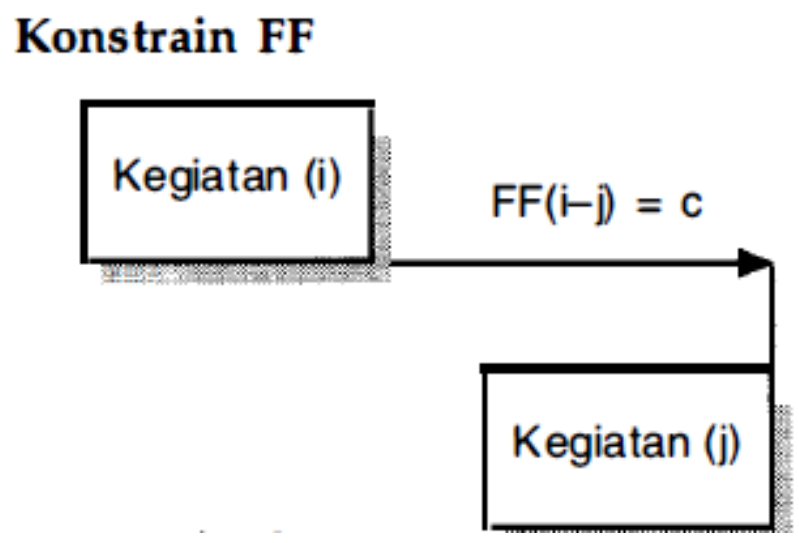

Gambar 5. Konstrain Finish to Finish

\section{Biaya Proyek}

Pada saat proyek konstruksi berlangsung, biaya proyek merupakan suatu hal yang sangat penting dan mendasar. Jumlah tenaga kerja dan alat yang digunakan merupakan dua dari banyak hal yang mempengaruhi besar atau kecilnya biaya proyek yang harus dikeluarkan. Biaya proyek terbagi menjadi dua, yakni biaya langsung (direct cost) dan biaya tidak langsung (indirect cost) (Priyo, 2018).

Biaya langsung merupakan biaya yang diperlukan langsung untuk mendapatkan sumber daya yang akan dipergunakan untuk penyelesaian proyek. Ketika durasi proyek ditentukan atau dipercepat, biaya langsung akan lebih tinggi dibanding durasi proyek yang dikembangkan dari waktu normal ideal untuk aktivitas (Priyo, 2018). Komponen biaya langsung terdiri dari biaya upah pekerja, operasi peralatan, material. Kategori yang termasuk biaya langsung adalah semua biaya yang berada di dalam kendali subkontraktor.

Biaya tidak langsung merupakan biaya yang berhubungan dengan pengawasan, pengarahan kerja, dan pengeluaran umum diluar biaya konstruksi. Biaya ini juga disebut sebagai overhead. Biaya ini tidak tergantung pada volume pekerjaan, tetapi tergantung pada jangka waktu pelaksanaan pekerjaan (Priyo, 2018). Biaya ini umumnya tidak tertera dalam daftar item pembayaran dalam kontrak atau tidak dirinci. Kategori yang termasuk biaya tidak langsung adalah biaya overhead, pajak (taxes), biaya umum (general conditions), dan biaya risiko. Biaya risiko adalah elemen biaya yang mengandung dan atau dipengaruhi ketidakpastian yang cukup tinggi, seperti biaya tak terduga (contingencies) dan keuntungan (profit).

\section{Hubungan Antara Biaya dan Waktu}

Biaya total proyek sama dengan penjumlahan dari biaya langsung dan tidak langsung. Biaya total proyek bergantung pada waktu penyelesaian proyek (Priyo, 2018) 


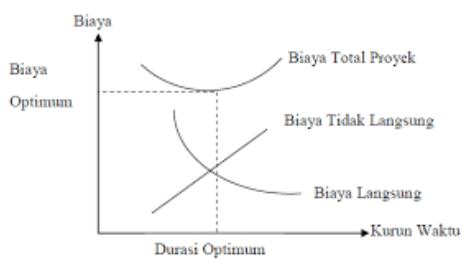

Gambar 6. Grafik hubungan biaya total, biaya langsung, tidak langsung dan waktu (Sumber: Priyo, 2018)

Terdapat tiga langkah untuk mengkonfigurasi grafik hubungan biaya total, biaya langsung, biaya tidak langsung dan waktu yaitu (Priyo, 2018):

1. Mencari total biaya langsung untuk lamanya proyek yang telah dipilih, contohnya biaya pegawai dan peralatan.

2. Mencari total biaya tak langsung untuk lamanya proyek yang telah dipilih, contohnya biaya administrasi dan konsultasi.

\section{Time Cost Trade Off}

Pada kegiatan di proyek, variabel biaya mempunyai peranan yang sangat penting, dimana biaya yang timbul harus dikendalikan seminimum mungkin. Pengendalian biaya harus memperhatikan waktu, karena terdapat hubungan yang erat antara waktu penyelesaian proyek dan biaya yang timbul.

Mempercepat durasi akan menambah biaya yang dibutuhkan, maka perlu dipelajari analisa percepatan dengan metode pertukaran waktu (time cost trade off). Ada beberapa macam strategi yang dapat dilakukan untuk melaksanakan percepatan penyelesaian waktu proyek. Strategi tersebut antara lain (Priyo, 2018):

1. Penambahan jam kerja (lembur)

2. Penambahan tenaga kerja

3. Pergantian atau penambahan alat

4. Pemilihan sumber daya yang berkualitas

5. Penggunaan metode konstruksi yang efektif.

\section{Strategi yang Diuji}

Penelitian ini menguji dua dari lima cara yang tersedia di atas. Pemilihan cara tentunya disesuaikan dengan kondisi lapangan dan penyebab keterlambatan pada basement lantai 7 proyek Indonesia 1. Keterlambatan terjadi dikarenakan hujan lebat yang menyebabkan kondisi tanah pada saat itu menjadi basah, sehingga tidak memungkinkan untuk dilakukan penggalian. Kemudian, kedalaman basement lantai 7 menjadi hambatan untuk mempercepat penyelesaian waktu proyek dengan penambahan produktivitas alat. Namun, luas lahan pada basement lantai 7 memungkinkan untuk dilakukan percepatan waktu proyek dengan menambah jumlah tenaga kerja. Dengan melihat kondisi lapangan dan penyebab keterlambatan waktu proyek pada basement lantai 7, strategi yang dapat dilakukan adalah dengan cara menambah jumlah tenaga kerja dan menambah jam kerja (lembur). 


\section{Penelitian Terdahulu}

Tabel 1. Daftar penelitian terdahulu

\begin{tabular}{|c|c|c|c|}
\hline No. & $\begin{array}{l}\text { Peneliti } \\
\text { (Tahun) }\end{array}$ & Metode Penelitian & Hasil Penelitian \\
\hline 1. & $\begin{array}{c}\text { Tanubrata, } \\
2015\end{array}$ & Kepustakaan & $\begin{array}{l}\text { 1. Pelaksanaan struktur basement ada } 2 \\
\text { metode, yaitu top down dan bottom up. } \\
\text { 2. Pada pelaksanaan metode top down } \\
\text { pekerjaan galian tanah dilakukan } \\
\text { bersamaan dengan pekerjaan struktur. }\end{array}$ \\
\hline 2. & $\begin{array}{l}\text { Bagaskara, } \\
2014\end{array}$ & $\begin{array}{l}\text { Membandingkan data } \\
\text { - data sekunder dari } \\
\text { kedua proyek tersebut } \\
\text { dengan mengacu } \\
\text { kepada studi pustaka. } \\
\text { Selain itu pada analisis } \\
\text { data ini digunakan } \\
\text { juga data primer } \\
\text { sebagai pendukung } \\
\text { untuk analisis lebih } \\
\text { lanjut yang bersifat } \\
\text { validasi }\end{array}$ & $\begin{array}{l}\text { 1. Alasan proyek menggunakan metode } \\
\text { pelaksanaan top down: luas lahan yang } \\
\text { terbatas dan lantai basement berjumlah } \\
5 \text { lantai dengan kedalaman sekitar } 20 \\
\text { meter, open cut agak sulit } \\
\text { dilaksanakan. } \\
\text { 2. Metode top down memiliki waktu } \\
\text { pelaksanaan yang lebih lama } \\
\text { dibandingkan dengan metode bottom } \\
\text { up. } \\
\text { 3. Metode top down mengeluarkan biaya } \\
\text { yang lebih mahal karena adanya } \\
\text { pembuatan king post dan pelat lantai } \\
\text { basement } 1 \text { yang harus tebal. }\end{array}$ \\
\hline 3. & Priyo, 2018 & $\begin{array}{l}\text { Pengumpulan data } \\
\text { (RAB, Analisa harga } \\
\text { satuan bahan, time } \\
\text { schedule) dari } \\
\text { konsultan, kontraktor. } \\
\text { Analisis dengan } \\
\text { menggunakan } \\
\text { program }\end{array}$ & $\begin{array}{l}\text { 1. Penerapan metode time cost trade off } \\
\text { dilakukan dengan variasi penambahan } \\
\text { jam kerja dan penambahan tenaga } \\
\text { kerja. } \\
\text { 2. Biaya dan durasi paling optimal di } \\
\text { dapat penambahan tenaga kerja selama } \\
\text { 3 jam, dibandingkan menambah jam } \\
\text { lembur. }\end{array}$ \\
\hline 4 & $\begin{array}{c}\text { Handayani, } \\
2017\end{array}$ & $\begin{array}{l}\text { Metode pengumpulan } \\
\text { data primer berupa } \\
\text { wawancara dengan } \\
\text { pihak kontraktor, data } \\
\text { sekunder berupa kurva } \\
\text { S, RAB, daftar satuan } \\
\text { upah, dan jumlah } \\
\text { pekerja }\end{array}$ & $\begin{array}{l}\text { 1. Penambahan jam kerja lembur dapat } \\
\text { menghemat waktu selama } 54 \text { hari dan } \\
\text { selisih biaya Rp112.688.051 } \\
\text { 2. Penambahan jumlah alat berat } \\
\text { mempunyai selisih waktu } 33 \text { hari dan } \\
\text { menghemat biaya sebesar } \\
\text { Rp.6.133.454 }\end{array}$ \\
\hline \multirow[t]{2}{*}{5} & Lafiza, 2017 & $\begin{array}{l}\text { Pengumpulan data dan } \\
\text { analisis data }\end{array}$ & $\begin{array}{l}\text { 1. Metode konstruksi top down dapat } \\
\text { dapat mereduksi waktu pelaksanaan } \\
\text { hingga } 15 \%\end{array}$ \\
\hline & & & $\begin{array}{l}\text { 2. Metode konstruksi top down } \\
\text { membutuhkan biaya yang lebih mahal } \\
\text { dibandingkan metode bottom up. }\end{array}$ \\
\hline
\end{tabular}

\section{METODE PENELITIAN}

Metode yang digunakan untuk melakukan percepatan durasi pekerjaan basement semi top down adalah menggunakan metode time cost trade off. Objek pada penelitian ini secara khusus adalah proyek konstruksi gedung 
bertingkat dengan basement semi top down dan proyek tersebut mengalami keterlambatan waktu penyelesaian pada pekerjaan basement. Proyek yang memenuhi syarat untuk penelitian ini ialah proyek Indonesia 1, Jakarta Pusat.

Pengumpulan data dilakukan dengan melakukan survey lapangan dan mewawancara engineer proyek Indonesia 1. Setelah semua data terkumpul, maka akan dilakukan percepatan dengan dua strategi yang terdapat dalam metode time cost trade off, yakni: menambah jumlah pekerja (strategi 1) dan menambah jam kerja (strategi 2).

Tahapan penelitian meliputi:

Pengumpulan data (jaringan kerja, biaya normal pekerja dan biaya lembur) basement semi top down
a. Membuat jaringan kerja berupa PDM dari barchart yang sudah didapat
b. Analisa Lintasan Kritis berdasarkan total float
c. Menguji Strategi Percepatan yang Tersedia Dari Metode Time Cost Trade Off, yaitu menambah jumlah tenaga kerja (strategi 1) dan menambah jumlah jam kerja (strategi 2)
d. Hitung Crash Duration dan Crash Cost untuk strategi 1 dan 2
e. Proses Perhitungan Cost Slope untuk strategi 1 dan 2
f. Mengurutkan Cost Slope dari yang terkecil untuk strategi 1 dan 2
g. Membuat jaringan kerja PDM dipercepat untuk strategi 1 dan 2
h. Menghitung Durasi Total Proyek untuk strategi 1 dan 2
i. Membandingkan strategi 1 dan 2 berdasarkan nilai crash cost dan durasi total proyek setelah dipercepat
j. Pilih strategi terbaik
k. Kesimpulan

\section{HASIL DAN PEMBAHASAN}

Percepatan durasi proyek dilakukan pada pekerjaan-pekerjaan kritis, sehingga ketika dilakukan percepatan akan mempengaruhi durasi total proyek. Strategi-strategi yang dapat dilakukan adalah dengan menambah jumlah pekerja dan menambah jumlah jam kerja. Biaya material dianggap sama karena menggunakan material yang sama dengan durasi normal. Pada jaringan kerja durasi normal berupa PDM, pekerjaan kritis adalah pekerjaan dengan total total float nol. Adapun pekerjaan-pekerjaan kritis adalah sebagai berikut:

1. Pekerjaan Galian Tower Area

2. Pekerjaan Galian Zona C

3. Pekerjaan Penulangan Pile Cap dan Slab Zona C

4. Pekerjaan Penulangan Kolom Zona C

5. Pekerjaan Pengecoran Pile Cap dan Slab Zona C

6. Pekerjaan Pengecoran Shearwall Zona C

7. Pekerjaan Pengecoran Kolom Zona C

8. Pekerjaan Ramp

Percepatan pekerjaan kritis di atas dilakukan berdasarkan hasil wawancara dengan engineer proyek Indonesia 1. Berdasarkan hasil wawancara, didapatkan hasil bahwa ada beberapa dari pekerjaan-pekerjaan kritis di atas yang tidak dapat dipercepat dikarenakan terbatasnya lahan yang tersedia untuk menyimpan material dan terbatasnya akses lalu lintas. Berikut ialah daftar pekerjaan yang tidak dapat dipercepat:

1. Pekerjaan Penulangan Pile Cap dan Slab Zona C

2. Pekerjaan Pengecoran Pile Cap dan Slab Zona C

3. Pekerjaan Pengecoran Shearwall Zona C

4. Pekerjaan Pengecoran Kolom Zona C

5. Pekerjaan Ramp

6. Pekerjaan Galian Tower Area.

Pekerjaan Galian Tower Area juga tidak dapat dipercepat. Hal itu dikarenakan pengurangan durasi pekerjaan galian Tower Area tidak mengurangi durasi total pekerjaan basement lantai 7. Jadi pekerjaan yang dapat dipercepat hanya tersisa 2, yaitu pekerjaan galian Zona $\mathrm{C}$ dan penulangan kolom Zona $\mathrm{C}$.

\section{Analisis Data Penambahan Jumlah Tenaga Kerja}

Contoh perhitungan sebagai berikut:

Pekerjaan: Galian Zona C dengan volume 6470,940 $\mathrm{m}^{3}$ 
Durasi normal: 44 hari.

Langkah perhitungan:

1. Menentukan upah pekerja durasi normal perhari.

Tabel 2. Upah Pekerja Durasi Normal Perhari

\begin{tabular}{cccc}
\hline Pekerja & $\begin{array}{c}\text { Jumlah } \\
\text { Pekerja }\end{array}$ & $\begin{array}{c}\text { Harga Satuan } \\
\text { Pekerja }\end{array}$ & $\begin{array}{c}\text { Biaya Upah } \\
\text { Pekerja }\end{array}$ \\
\hline Tukang Gali & 3 & Rp 138.077 & Rp 414.231 \\
\hline Tukang Angkut & 2 & Rp 138.077 & Rp 276.154 \\
\hline Mandor & 1 & Rp 185.023 & Rp 185.023 \\
\hline Total Upah Pekerja Durasi Normal Perhari & Rp 875.408 \\
\hline
\end{tabular}

2. Produktivitas sebelum crashing $=\left(\frac{6470.940}{44} \frac{\mathrm{m}^{3}}{\text { hari }}\right)=147.07 \mathrm{~m}^{3} /$ hari.

3. Produktivitas harian setelah crashing $=\left(\frac{147.07 \times 12}{6}\right)=294.14 \mathrm{~m}^{3} / \mathrm{hari}$.

4. Crash duration $=\left(\frac{6470.940 \mathrm{~m}^{3}}{297.14 \mathrm{~m}^{3} / \text { hari }}\right)=22$ hari

5. Menentukan nilai Crash Cost Pekerja

Tabel 3. Crash Cost Pekerja Akibat Percepatan Selama 7 Hari

\begin{tabular}{cccc}
\hline Pekerja & $\begin{array}{c}\text { Jumlah } \\
\text { Pekerja }\end{array}$ & Harga Satuan Pekerja & Biaya Upah Pekerja \\
\hline Tukang Gali & $(3+4)$ & Rp 138.077 & Rp 966.539 \\
\hline Tukang Angkut & $(2+2)$ & Rp 138.077 & Rp 552.308 \\
\hline Mandor & 1 & Rp 185.023 185.023 \\
\hline Crash Cost Pekerja Akibat Percepatan Perhari & Rp 1.703.870 \\
\hline Crash Cost Pekerja Akibat Percepatan Selama 7 Hari & Rp 11.927.090
\end{tabular}

6. Cost Slope $=\left(\frac{R p 1.703 .870-R p 875.408}{44-37}\right)=\mathrm{Rp} 118.451$

Tabel 4. Cost Slope Tiap Pekerjaan Akibat Penambahan Jumlah Tenaga Kerja

\begin{tabular}{cccccccc}
\hline No & Pekerjaan & $\begin{array}{c}\text { Durasi } \\
\text { Normal }\end{array}$ & $\begin{array}{c}\text { Durasi } \\
\text { Crash }\end{array}$ & $\begin{array}{c}\text { Durasi } \\
\text { Percepatan }\end{array}$ & Normal Cost & Crash Cost & Cost Slope \\
\hline 1 & Galian Zona C & 44 hari & 37 hari & 7 hari & Rp 875.408 & Rp 1.703.870 & Rp 118.352 \\
\hline 2 & $\begin{array}{l}\text { Penulangan Kolom } \\
\text { Zona C }\end{array}$ & 54 hari & 47 hari & 7 hari & Rp 1.198.513 & Rp 2.181.625 & Rp 140.445 \\
\hline
\end{tabular}




\section{Analisa Data Penambahan Jumlah Jam Kerja}

Pekerjaan: Galian Zona C dengan volume 6470,940 $\mathrm{m}^{3}$

Durasi normal: 44 hari.

Langkah perhitungan:

1. Menentukan upah pekerja durasi normal perhari.

Tabel 5. Upah Pekerja Durasi Normal Perhari

\begin{tabular}{cccc}
\hline Pekerja & $\begin{array}{c}\text { Jumlah } \\
\text { Pekerja }\end{array}$ & $\begin{array}{c}\text { Harga Satuan } \\
\text { Pekerja }\end{array}$ & $\begin{array}{c}\text { Biaya Upah } \\
\text { Pekerja }\end{array}$ \\
\hline Tukang Gali & 3 & Rp 138.077 & Rp 414.231 \\
\hline Tukang Angkut & 2 & Rp 138.077 & Rp 276.154 \\
\hline Mandor & 1 & Rp 185.023 & Rp 185.023 \\
\hline Total Upah Pekerja Durasi Normal Perhari & Rp 875.408 \\
\hline
\end{tabular}

2. Produktivitas sebelum crashing $=\left(\frac{6470.940}{44} \frac{\mathrm{m}^{3}}{\text { hari }}\right)=147.07 \mathrm{~m}^{3} /$ hari.

3. Produktivitas perjam $=\left(\frac{147.07 \mathrm{~m}^{3}}{8 \mathrm{jam}}\right)=18.38 \mathrm{~m}^{3} / \mathrm{jam}$

4. Menentukan produktivitas harian setelah crashing

Tabel 6. Koefisien Penurunan Produktivitas

\begin{tabular}{lcc}
\hline Jam & Penurunan & Prestasi \\
\hline 1 jam & 0,1 & 90 \\
\hline 2 jam & 0,2 & 80 \\
\hline 3 jam & 0,3 & 70 \\
\hline 4 jam & 0,4 & 60 \\
\hline
\end{tabular}

Jadi, produktivitas harian setelah crashing $=(8 \times 18.38)+(3 \times 0.7 \times 18.38)=185.638 \mathrm{~m}^{3} /$ hari.

5. Crash duration $=\left(\frac{6470.940 \mathrm{~m}^{3}}{185.638 \mathrm{~m}^{3} / \text { hari }}\right)=34.85$ hari $\approx 38$ hari

6. Menentukan upah normal seluruh pekerja

Tabel 7. Upah Normal Seluruh Pekerja Perjam

\begin{tabular}{lccc}
\hline \multicolumn{1}{c}{ Pekerja } & $\begin{array}{c}\text { Harga Satuan } \\
\text { Pekerja }\end{array}$ & $\begin{array}{c}\text { Jumlah Jam } \\
\text { Kerja }\end{array}$ & $\begin{array}{c}\text { Upah Normal } \\
\text { Per Jam }\end{array}$ \\
\hline Tukang Gali & Rp 138.077 & & Rp 17.260 \\
\cline { 1 - 2 } Tukang Angkut & Rp 138.077 & jam per hari & Rp 17.260 \\
\cline { 1 - 2 } Mandor & Rp 185.023 & & Rp 23.128 \\
\hline
\end{tabular}

7. Menentukan upah lembur seluruh pekerja

Upah lembur 1 tukang gali $=1.5 \times \operatorname{Rp} 17.260+2 \times 3 \times \operatorname{Rp} 17.260$

$$
=\operatorname{Rp} 129.450
$$

Upah lembur 3 tukang gali $=$ Rp 129.450 × $3=$ Rp 388.350 
Tabel 8. Upah Lembur Seluruh Pekerja

\begin{tabular}{|c|c|c|c|c|}
\hline Pekerja & $\begin{array}{c}\text { Upah Normal } \\
\text { Per Jam }\end{array}$ & $\begin{array}{c}\text { Jumlah Jam } \\
\text { Lembur }\end{array}$ & Jumlah Pekerja & $\begin{array}{c}\text { Upah Lembur } \\
\text { Pekerja }\end{array}$ \\
\hline Tukang Gali & Rp 17.260 & \multirow{3}{*}{$\begin{array}{c}3 \text { jam selama } \\
27 \text { hari }\end{array}$} & 3 & Rp 388.350 \\
\hline Tukang Angkut & $\mathrm{Rp} 17.260$ & & 2 & $\mathrm{Rp} 258.900$ \\
\hline Mandor & $\operatorname{Rp} 23.128$ & & 1 & $\mathrm{Rp} 173.460$ \\
\hline & Total & & 6 & $\mathrm{Rp} 820.710$ \\
\hline & 127 Hari Lembu & & 6 & $\operatorname{Rp} 22.159 .170$ \\
\hline
\end{tabular}

8. Menentukan Crash Cost Pekerja

Tabel 9. Crash Cost Pekerja Akibat Percepatan Selama 7 Hari

\begin{tabular}{cccc}
\hline Pekerja & $\begin{array}{c}\text { Jumlah Jam } \\
\text { Kerja }\end{array}$ & Harga Satuan Pekerja & Biaya Upah Pekerja \\
\hline Tukang Gali & $(8+3)$ & Rp 138.077 & Rp 802.581 \\
\hline Tukang Angkut & $(8+3)$ & Rp 138.077 & Rp 535.054 \\
\hline Mandor & $(8+3)$ & Rp 185.023 & Rp 358.483 \\
\hline Crash Cost Pekerja Akibat Percepatan Perhari & Rp 1.696.118 \\
\hline \multicolumn{2}{c}{ Crash Cost Pekerja Akibat Lembur 27 hari } & Rp 45.795.186
\end{tabular}

Crash cost tukang gali : Rp 414.231 + Rp 388.350 = Rp 802.581

9. $\quad$ cost slope galian Zona $\mathrm{C}=(\mathrm{Rp} 1.696 .118-\mathrm{Rp} 875.408) /(44-37)$

$=\operatorname{Rp} 117.245$

Tabel 10. Nilai Cost Slope Tiap Pekerjaan Akibat Penambahan Jam Kerja

\begin{tabular}{lccr}
\hline No & Pekerjaan & $\begin{array}{c}\text { Kemungkinan } \\
\text { Dipercepat }\end{array}$ & Cost Slope \\
\hline 1 & Galian Zona C & 7 hari & Rp 117.245 \\
\hline 2 & Penulangan Kolom Zona C & 7 hari & Rp 160.515 \\
\hline
\end{tabular}

\section{Pembahasan}

Percepatan pada strategi 1 dan 2 dilakukan berdasarkan hasil wawancara dengan seorang engineer proyek Indonesia 1. Hasil wawancara tersebut ialah percepatan pekerjaan galian Zona $\mathrm{C}$ dan pekerjaan penulangan kolom Zona $\mathrm{C}$ hanya dapat dilakukan maksimal 14 hari kerja.

Pada strategi 1 dilakukan percepatan durasi pekerjaan dengan menambah jumlah pekerja di tiap pekerjaan kritis. Setelah menganalisis pekerjaan galian Zona C didapatkan hasil bahwa ketika menambah pekerja sebanyak tiga orang akan mempercepat durasi dari 44 hari menjadi 30 hari atau sebanyak 14 hari. Maka dilakukanlah percobaan, hasil yang didapat dari percobaan ialah menambah tiga pekerja akan mempercepat durasi pekerjaan selama 14 hari dengan nilai crash cost total sebesar Rp 18.054.946. Kemudian dicoba dengan menambah 6 pekerja selama tujuh hari kerja menghasilkan nilai crash cost total yang lebih kecil yaitu sebesar Rp 11.927.090, sehingga dipilih menambah enam pekerja selama tujuh hari.

Pada strategi 2, dicoba dengan menambah jam kerja sebanyak tiga jam perhari dan dilakukan selama 27 hari. Penambahan jam kerja lembur dilakukan selama 27 hari agar pekerjaan galian Zona $\mathrm{C}$ dapat selesai dengan durasi pekerjaan sebanyak 37 hari dan sesuai dengan volume pekerjaan yaitu sebesar $6470.940 \mathrm{~m} 3$. Menambah jam kerja tiga hari perhari selama 27 hari menghasilkan nilai crash cost total sebesar Rp 45.795.186. 
Berdasarkan nilai crash cost total yang dihasilkan dari kedua strategi, maka mempercepat durasi pekerjaan akan dilakukan dengan menambah jumlah tenaga kerja. Hal itu dikarenakan menambah jumlah tenaga kerja (strategi 1) menghasilkan nilai crash cost total yang lebih kecil jika dibandingan dengan nilai crash cost total dari menambah jumlah jam kerja.

Percepatan durasi pada pekerjaan penulangan kolom Zona C dilakukan berdasarkan wawancara dengan seorang engineer proyek Indonesia 1. Berdasarkan hasil wawancara, pekerjaan penulangan kolom Zona $\mathrm{C}$ hanya dapat dilaksanakan maksimal 14 hari kerja. Hal tersebut dikarenakan terbatasnya lahan yang tersedia untuk menyimpan alat dan bahan. Pada strategi 1, pekerjaan penulangan kolom Zona C, menambah tiga orang pekerja akan mengurangi durasi selama 15 hari. Namun, percepatan tetap dilaksanakan selama 14 hari kerja sesuai dengan hasil wawancara. Nilai crash cost total yang didapat dari menambah tiga orang pekerja selama 14 hari ialah sebesar Rp 23.660.966. Kemudian dicoba dengan menambah enam pekerja selama tujuh hari. Nilai crash cost total yang dihasilkan sebesar Rp 15.271.375. Nilai crash cost total yang dihasilkan dari menambah enam orang pekerja selama tujuh hari lebih kecil dibandingkan dengan menambah tiga pekerja selama 14 hari. Sehingga, berdasarkan nilai crash cost total akan dipilih menambah enam pekerja selama tujuh hari.

Pada strategi 2, dicoba dengan menambah jam kerja sebanyak tiga jam perhari akan mengurangi durasi pekerjaan dari 44 hari menjadi 35 hari. Namun, percepatan pada strategi 2 dilakukan sesuai dengan durasi percepatan pada strategi 1, yaitu selama tujuh hari kerja. Hal itu dilakukan agar nilai crash cost total dari strategi 1 dan strategi 2 dapat dibandingkan karena memiliki durasi percepatan yang sama. Penambahan jam kerja lembur dilakukan selama 28 hari kerja agar pekerjaan penulangan kolom Zona $\mathrm{C}$ dapat selesai dengan durasi pekerjaan sebanyak 47 hari dan sesuai dengan volume pekerjaan yaitu sebesar $1775 \mathrm{~kg}$. Menambah jam kerja tiga hari perhari selama 28 hari menghasilkan nilai crash cost total sebesar Rp 65.019.330.

Penjelasan di atas kemudian disederhanakan ke dalam bentuk grafik 1 yang menampilkan masing-masing nilai crash cost yang dihasilkan dari strategi 1 maupun strategi 2.

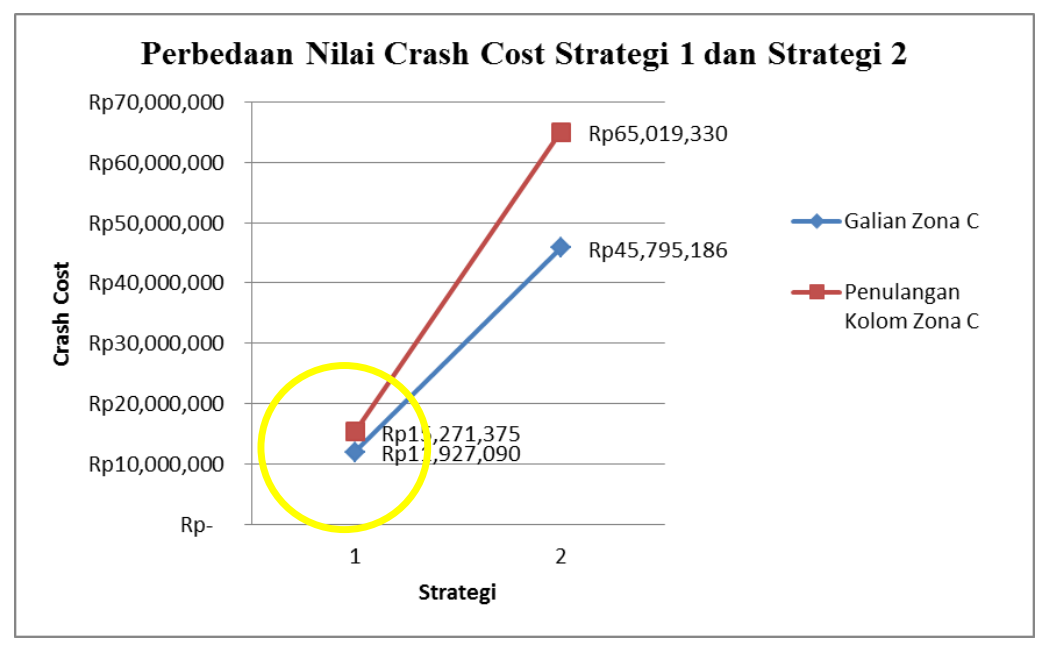

Gambar 7. Perbedaan Nilai Crash Cost Strategi 1 dan Strategi 2

Berdasarkan grafik, dapat dilihat titik berwarna biru di dalam lingkaran kuning menunjukan pekerjaan Galian Zona C memiliki nilai crash cost sebesar Rp 11.927.090. Sedangkan pada strategi 2, pekerjaan Galian Zona C memiliki nilai crash cost sebesar Rp 45.795.186. Titik berwarna merah di dalam lingkaran kuning menunjukan pekerjaan Penulangan Kolom Zona C memiliki nilai crash cost sebesar Rp 15.271.375. Sedangkan pada strategi 2, pekerjaan Penulangan Kolom Zona C memiliki nilai crash cost sebesar Rp 65.019.330. Sehingga dapat dikatakan bahwa strategi 1 untuk pekerjaan Galian Zona C dan Penulangan Kolom Zona C memiliki nilai crash cost yang lebih murah jika dibandingkan dengan nilai crash cost pada strategi 2. Oleh karena itu, baik pekerjaan galian Zona C maupun pekerjaan penulangan kolom Zona $\mathrm{C}$ lebih baik dipercepat dengan menambah jumlah pekerja(strategi 1).

\section{KESIMPULAN DAN SARAN}

\section{Kesimpulan}

Kesimpulan dari hasil penelitian ini adalah sebagai berikut:

1. Pekerjaan kritis dapat dipercepat apabila kondisi di lapangan juga memungkinkan pekerjaan tersebut dipercepat. Jadi tidak semua pekerjaan kritis dapat dilakukan percepatan. 
2. Strategi yang dipilih ialah strategi 1 baik untuk pekerjaan Galian Zona C maupun pekerjaan Penulangan Kolom Zona C. Strategi 1 dipilih karena menghasilkan nilai crash cost yang lebih murah jika dibandingkan dengan nilai crash cost strategi 2.

\section{Saran}

Berdasarkan hasil penelitian yang didapatkan, berikut saran-saran untuk kontraktor dan penelitian berikutnya:

1. Untuk kontraktor proyek Indonesia 1, apabila ingin mengatasi keterlambatan lebih baik menggunakan strategi percepatan dengan menambah jumlah tenaga kerja.

2. Selain menggunakan strategi percepatan dengan menambah jumlah tenaga kerja dan menambah jumlah jam lembur, penggunaan alat dan metode lain pun dapat digunakan. Sehingga dapat mengurasi durasi pekerjaan semaksimal mungkin.

3. Penelitian ini dilakukan pada konstruksi gedung bertingkat, untuk itu selanjutnya diharapkan penelitian ini dapat dilakukan pada proyek sipil lainnya seperti jembatan, bendungan, atau bangunan infrastruktur lainnya.

\section{DAFTAR PUSTAKA}

Bagaskara, M., A. Wibowo, dan N. A. Bintang. Kajian Pemilihan Pekerjaan Basement Pada Bangunan Bertingkat Tinggi Menggunakan Top Down Sebagai Inovasi Metode Pelaksanaan (Studi Kasus: Proyek Sudirman Suites Hotel And Apartment Jakarta). Jurnal Karya Teknik Sipil Vol. 3, 950-955, Semarang: Universitas Diponegoro, 2014.

Dokumen Proyek Indonesia 1, Foundation Plan. Jakarta: PT. Davy Sukamta Konsultan, 2015.

Handayani, F., W. Kisworo dan Sunarmasto, “Analisis Percepatan Proyek Menggunakan Metode Time Cost Trade Off Dengan Penambahan Jam Kerja Lembur dan Jumlah Alat", Surakarta: Universitas Sebelas Maret, 2017.

Lafiza, A., “Analisa Perbandingan Metode Top Down dan Bottom Up Pada Proyek Fave Hotel Ketintang Ditinjau Dari Segi Biaya Dan Waktu", Surabaya: Institut Teknologi Sepuluh Nopember, 2017.

Kustiani, I., A. Ma'ruf, dan I. Kustiani, “Analisis Time Cost Trade Off Untuk Mengejar Keterlambatan Pelaksanaan Proyek Di Bandar Lampung”, Vol. 20, Jurnal Rekayasa, 2016.

Priyo, Mandiyo dan Meiki R. A. Paridi. 2018. Studi Optimasi Waktu dan Biaya dengan Metode Time Cost Trade Off pada Proyek Konstruksi Pembangunan Gedung Olah Raga (Gor). Semesta Teknika Vol. 21, 72 - 84.

Tanubrata, M., "Pelaksanaan Konstruksi Dengan Sistem Top Down", Bandung: Simposium Nasional RAPI XIV, 2015.

Excavation Methods For Deep Foundation, https://theconstructor.org/practical-guide/excavation-methods-deepfoundations/21157/ Madeh Izat Hamakareem, 2019, diunduh pada tanggal 18 Agustus 2019, 13:06 